\title{
Phase I study of weekly palliative chemotherapy with low-dose third-line paclitaxel for biliary tract cancer
}

\author{
HIDEHIRO TAJIMA ${ }^{1}$, TETSUO OHTA ${ }^{1}$, HIROYUKI SHINBASHI ${ }^{1}$, ATSUSHI HIROSE ${ }^{1}$, \\ MITSUYOSHI OKAZAKI $^{1}$, TAKAHISA YAMAGUCHI ${ }^{1}$, YOSHINAO OHBATAKE ${ }^{1}$, KOICHI OKAMOTO ${ }^{1}$, \\ SHINICHI NAKANUMA ${ }^{1}$, SEISHO SAKAI ${ }^{1}$, JUN KINOSHITA ${ }^{1}$, ISAMU MAKINO ${ }^{1}$, KEISHI NAKAMURA ${ }^{1}$, \\ HIRONORI HAYASHI ${ }^{1}$, KATSUNOBU OYAMA ${ }^{1}$, MASAFUMI INOKUCHI ${ }^{1}$, TOMOHARU MIYASHITA ${ }^{1}$, \\ HIROYUKI TAKAMURA $^{1}$, ITASU NINOMIYA ${ }^{1}$, SACHIO FUSHIDA ${ }^{1}$ and HIROYUKI NAKAMURA ${ }^{2}$
}

Departments of ${ }^{1}$ Gastroenterological Surgery, and ${ }^{2}$ Environmental and Preventive Medicine,
Graduate School of Medical Science, Kanazawa University, Kanazawa, Ishikawa 920-8641, Japan

Received September 7, 2016; Accepted January 31, 2017

DOI: $10.3892 / \mathrm{mco} .2017 .1206$

\begin{abstract}
The prognosis of patients with unresectable and recurrent biliary tract cancer (BTC) is very poor. Although gemcitabine (GEM) plus cisplatin therapy is useful for unresectable cases, the median overall survival (OS) of the patients is $<1$ year, and third-line chemotherapy following failure of 5-fluorouracil (5-FU) and GEM plus cisplatin is currently unavailable. The clinical efficacy and basic effects of low-dose paclitaxel (PTX) therapy for patients with BTC was previously reported. We herein present the results of a phase I clinical trial of weekly low-dose PTX as third-line palliative chemotherapy. PTX was administered on days $1,8,15$ and 22 of each cycle and repeated twice as follows: Level $1,40 \mathrm{mg} / \mathrm{m}^{2}$; level $2,50 \mathrm{mg} / \mathrm{m}^{2}$ $(n=3)$. During the two cycles, grade 1 or 2 adverse events were observed in 3 patients, whereas dose-limiting adverse events (grade 3 or 4) were not observed. The disease control rate was $83.3 \%$ (partial response, $n=3$; stable disease, $n=2$ ). The OS and median survival were 15.4 and 9.0 months, respectively. In conclusion, palliative chemotherapy with low-dose PTX following failure of GEM and 5-FU was well-tolerated, safe and effective for patients with unresectable or recurrent BTCs, and the optimal dose was $50 \mathrm{mg} / \mathrm{m}^{2}$.
\end{abstract}

\section{Introduction}

Biliary tract cancers (BTCs) include carcinomas of the gallbladder, bile ducts (cholangiocarcinoma) and the papilla of Vater. The majority of BTCs are detected at an advanced

Correspondence to: Dr Hidehiro Tajima, Department of Gastroenterological Surgery, Graduate School of Medical Science, Kanazawa University, 13-1 Takaramaci, Kanazawa, Ishikawa 920-8641, Japan

E-mail: hidetaji@staff.kanazawa-u.ac.jp

Key words: biliary tract cancer, low-dose paclitaxel, third-line, palliative chemotherapy incurable stage and are typically treated with chemotherapy, such as 5-fluorouracil (5-FU), gemcitabine (GEM), cisplatin, or their combination. The response rates range between 20 and $40 \%$, with a median overall survival (OS) of 8-14 months (1). The most notable advance in the treatment of BTC was achieved by a phase III randomized trial demonstrating that doublet chemotherapy with GEM plus cisplatin improved the OS by 3.6 months vs. GEM alone (2). However, the median OS with GEM plus cisplatin is 11.7 months, and appropriate third-line chemotherapy following GEM (plus cisplatin) and $5-\mathrm{FU}$ is currently unavailable for the treatment of patients with BTC.

Paclitaxel (PTX) is an anticancer agent (3) that stabilizes polymerized microtubules and enhances microtubule assembly, arresting the cell cycle in G0/G1 and G2/M and leading to cell death $(4,5)$. Low-dose PTX ameliorates tissue fibrosis by inhibiting the activity of the transforming growth factor (TGF)- $\beta /$ Smad activity $(6,7)$. Therefore, it was hypothesized that PTX may be useful for the treatment of patients with BTC associated with tissue fibrosis.

It has been demonstrated that low-dose PTX inhibits the epithelial-to-mesenchymal transition (EMT) of cholangiocarcinoma cells treated with TGF- $\beta$ (8). Furthermore, we previously reported the response of a patient with gallbladder cancer with multiple liver metastases and stenosis of the bile duct to treatment with low-dose PTX as palliative chemotherapy following GEM and S-1 (oral prodrug of 5-FU) (9). Therefore, a phase I clinical trial was planned to determine the optimal dose of weekly low-dose PTX therapy as third-line chemotherapy for patients with BTC following failure of S-1 and GEM (plus cisplatin).

\section{Patients and methods}

Patient selection. Patients with unresectable (locally advanced or with distant metastases) or postoperative recurrent BTC treated with GEM (plus cisplatin) and S-1 were considered eligible for the study. Other inclusion criteria were as follows: Age 20-80 years, Eastern Cooperative Oncology Group performance status $\leq 1$ (ambulatory and capable of self-care), 
adequate renal function (normal serum creatinine and blood urea nitrogen levels), liver function [total bilirubin level, $<2.5$-times the upper limit of normal (ULN) or $<3$-times the ULN following biliary drainage, if the patient had jaundice and serum alanine aminotransferase and aspartate aminotransferase levels $<2.5$-times the ULN or $<3$-times the ULN following biliary drainage, if the patient had jaundice], bone marrow reserve (white blood cell count, 4,000-12,000 $\mathrm{mm}^{3}$; neutrophil count, $>2,000 \mathrm{~mm}^{3}$; platelet count, $>100,000 \mathrm{~mm}^{3}$; and hemoglobin level $>9.5 \mathrm{~g} / \mathrm{dl}$ ) and pulmonary function $\left(\mathrm{PaO}_{2},>70 \mathrm{mmHg}\right)$. If a patient had a history of treatment for BTC, such treatment (tumor resection, chemotherapy, immunotherapy or radiotherapy) must have been discontinued $\geq 2$ weeks prior to enrolment.

The exclusion criteria were as follows: Pulmonary fibrosis or interstitial pneumonia, marked pleural or pericardial effusion or marked peripheral edema, severe heart disease, difficult-to-control diabetes mellitus, active infection, pregnancy or lactation, women of childbearing age who did not use effective contraception, severe drug hypersensitivity, severe neurological impairment or mental disorder, active concomitant malignancy, previous history of PTX administration and other serious medical conditions.

Written informed consent was obtained from each patient prior to enrolment, and the study protocol was approved by the Institutional Review Board of Kanazawa University Hospital (UMIN ID: 000008148).

Study design. An open-label, single-center, non-randomized, dose-escalation phase I study was conducted. The laboratory tests to assess eligibility were completed within 7 days prior to commencing treatment. PTX was administered as a $60-\mathrm{min}$ intravenous infusion on days $1,8,15$ and 22 of each cycle. The cycle was repeated twice every 28 days. The dose of PTX was planned as follows: Level 1, $40 \mathrm{mg} / \mathrm{m}^{2}$; level $2,50 \mathrm{mg} / \mathrm{m}^{2}$ (Fig. 1). If the treatment was deemed as effective after two cycles, PTX therapy was continued weekly or biweekly for as long as possible.

Definition of dose-limiting toxicity (DLT) and maximum tolerated dose (MTD). DLT was determined during each treatment cycle and was defined according to the National Cancer Institute's Common Toxicity Criteria scale, version 4.0 (http://ctep.cancer.gov/protocolDevelopment/electronic_applications/ctc.htm\#ctc_40) as one or more of the effects attributable to the study drug as follows: i) Grade 3/4 neutropenia complicated by fever; ii) grade 4 neutropenia for $>4$ days; iii) grade 4 thrombocytopenia; iv) any other grade $3 / 4$ non-hematological toxicity, apart from anorexia, nausea and vomiting in the absence of an appropriate antiemetic; and $\mathrm{v}$ ) delay of recovery from treatment-related toxicity for $>2$ weeks. At least 3 patients were enrolled at each dose level. If DLT was observed after the first cycle in $>2$ patients, treatment at that dose was discontinued. If DLT was observed after the first cycle in 1 patient, 3 additional patients were placed on that dose level. If only 1 of 6 patients experienced DLT, dose escalation was continued. The MTD of the combination was defined as the dose that produced DLT in $>2$ of the 6 patients or in the 3 initial patients. The recommended dose (RD) was defined as the dose one level below the MTD, considering toxicity and tolerability to outpatients. If level 2 was lower than the MTD, further dose escalation was not performed, and level 2 became the RD, as the intent was palliation.

Assessment of efficacy. Tumor response was evaluated according to the Response Evaluation Criteria in Solid Tumors (10). Complete response (CR) was defined as the disappearance of clinical evidence of the tumor. Partial response (PR) was defined as a $\geq 30 \%$ reduction in the sum of the products of two orthogonal diameters of all measurable lesions compared with the baseline values, with no evidence of new lesions. Stable disease (SD) was defined as $<30 \%$ reduction or $<20 \%$ increase in the sum of the products of two orthogonal diameters of all measurable lesions compared with baseline values, with no evidence of new lesions. Progressive disease (PD) was defined as $\geq 20 \%$ increase in the sum of the products of two orthogonal diameters of all measurable lesions compared with baseline values, the appearance of a new lesion, or deterioration of clinical status consistent with disease progression. To assess objective response, the patients were evaluated after two cycles of chemotherapy, and the concentrations of the tumor markers carcinoembryonic antigen (CEA) and carbohydrate antigen (CA) 19-9 were measured before and after two treatment cycles.

Statistical analysis. The median survival time (MST) and OS were calculated from the treatment initiation until death from any cause and were determined using the Kaplan-Meier method. The significance of the differences in the data for CEA and CA19-9 concentrations were evaluated using the paired $t$-test after logarithmic transformation of the values and $\mathrm{P}<0.05$ was considered to indicate statistically significant differences. The SPSS statistical package (version 19; SPSS Inc., Chicago, IL, USA) was used to conduct the analyses.

\section{Results}

Patient characteristics. Between October, 2012 and May, 2013, a total of 6 patients ( 2 men and 4 women) diagnosed with BTC were enrolled in the present study. The patient characteristics and the effects of treatment are listed in Table I. Cases 1-5 were patients with postoperative recurrent BTC and case 6 was a patient with locally advanced gallbladder cancer case with liver metastases. Treatment was performed at level $1\left(40 \mathrm{mg} / \mathrm{m}^{2}\right)$ and level $2\left(50 \mathrm{mg} / \mathrm{m}^{2}\right)$ for 3 patients. The response to treatment were as follows: PR, 3/6 (50.0\%); $\mathrm{SD}, 2 / 6$ (33.3\%); and PD, 1/6 (16.7\%). The disease control rate $(\mathrm{PR}+\mathrm{SD})$ was $83.3 \%$. During the two courses of therapy, grade 1 or 2 adverse events were observed in all the patients; however, dose-limiting adverse events (grade 3 or 4 ) were not observed, and all the patients completed two courses of treatment. The adverse events were as follows: Hair loss $(100.0 \%)$, anemia (83.3\%), general malaise (66.7\%), as well as thrombocytopenia, diarrhea and joint pain (16.7\%). Significant neuropathy and neutropenia were not observed during the two treatment cycles (Table II).

The CEA concentrations prior to treatment were elevated to $>5 \mathrm{IU} / \mathrm{ml}$ (normal, $\leq 5 \mathrm{IU} / \mathrm{ml}$ ) in 4 of the 6 patients, and the CA-19-9 concentrations prior to treatment were elevated to $>37 \mathrm{IU} / \mathrm{ml}$ (normal, $\leq 37 \mathrm{IU} / \mathrm{ml}$ ) in 4 of the 6 patients. The CEA 
Table I. Patient characteristics and treatment effects.

\begin{tabular}{lcllccr}
\hline No. & Age, yrs & Gender & Primary tumor & $\begin{array}{c}\text { Dose } \\
\left(\mathrm{mg} / \mathrm{m}^{2}\right)\end{array}$ & $\begin{array}{c}\text { Treatment } \\
\text { effect }\end{array}$ & $\begin{array}{c}\text { TTF } \\
\text { (months) }\end{array}$ \\
\hline 1 & 73 & Female & Gallbladder & 40 & PR & 4 \\
2 & 65 & Female & Intrahepatic bile duct & 40 & SD & 9 \\
3 & 79 & Male & Cystic duct & 40 & PR & 14 \\
4 & 80 & Female & Intrahepatic bile duct & 50 & PD & 0 \\
5 & 65 & Male & Hilar bile duct & 50 & SD & 5 \\
6 & 57 & Female & Gallbladder & 50 & PR & 9 \\
\hline
\end{tabular}

TTF, timetotreatment failure; $\mathrm{PR}$, partial response; SD, stable disease; $\mathrm{PD}$, progressive disease.

Table II. Adverse events.

\begin{tabular}{lcc}
\hline Toxicity & Grade $1 / 2, \mathrm{n}(\%)$ & Grade 3/4 \\
\hline Neutropenia & $0(0.0)$ & 0 \\
Anemia & $4(66.7)$ & 0 \\
Thrombocytopenia & $1(16.7)$ & 0 \\
Anorexia & $0(0.0)$ & 0 \\
General malaise & $4(66.7)$ & 0 \\
Diarrhea & $1(16.7)$ & 0 \\
Neuropathy & $0(0.0)$ & 0 \\
Joint pain & $1(16.7)$ & 0 \\
Hair loss & $6(100.0)$ & - \\
\hline
\end{tabular}

Table III. Transition of tumor markers.

\begin{tabular}{lccc}
\hline $\begin{array}{l}\text { Tumor } \\
\text { markers }\end{array}$ & $\begin{array}{c}\text { Prior to } \\
\text { treatment } \\
(\text { mean } \pm \text { SE) }\end{array}$ & $\begin{array}{c}\text { After two } \\
\text { treatment cycles } \\
(\text { mean } \pm \text { SE) }\end{array}$ & P-value \\
\hline CEA $(\mathrm{IU} / \mathrm{ml})$ & $27.8( \pm 12.6)$ & $5.2( \pm 1.5)$ & 0.039 \\
CA19-9 $(\mathrm{IU} / \mathrm{ml})$ & $349.2( \pm 322.9)$ & $104.0( \pm 75.3)$ & 0.908
\end{tabular}

SE, standard error; CEA, carcinoembryonic antigen; CA, carbohydrate antigen.

and CA19-9 concentrations decreased in 4 and 2 patients, respectively, and the decrease in CEA concentration was significant $(\mathrm{P}=0.039)$ (Table III).

The OS and MST from treatment initiation until death were 15.4 (range, 6.5-31.1) and 9.0 months, respectively (Fig. 1).

\section{Discussion}

The prognosis of patients with unresectable and recurrent BTC is very poor, and standard chemotherapy for patients with unresectable BTC was not available until the discovery of the increased efficacy of cisplatin plus GEM cited above (2). However, the median OS of patients treated with cisplatin plus GEM was reported to be only 11.7 months (2). 5-FU is a

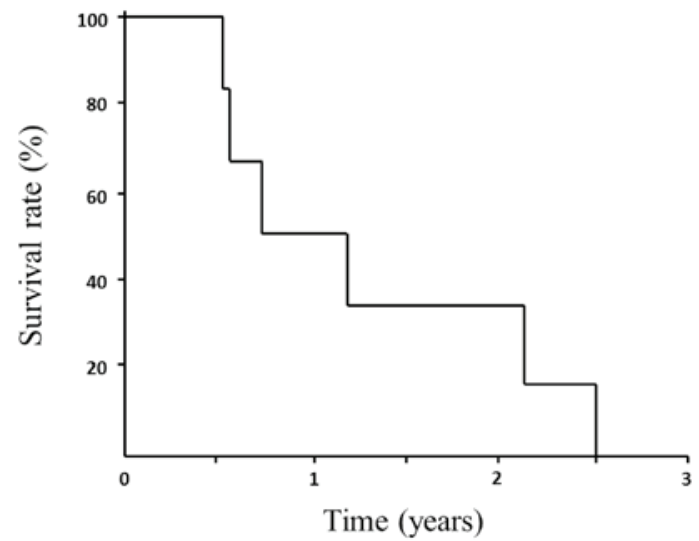

Figure 1. Overall survival (OS) curve for 6 patients with biliary tract cancer following induction using third-line chemotherapy with low-dose weekly paclitaxel. The OS and median survival from the start of treatment until death were 15.4 and 9.0 months, respectively.

major drug used to treat hepatobiliary and pancreatic cancers; however, phase II studies of combinations primarily based on 5-FU regimens show little or no benefit in terms of survival and quality of life $(11,12)$. S-1 is an oral prodrug of 5-FU that is widely used in Japan. In the phase III GEST trial, S-1 achieved a favorable response and was not inferior to GEM in increasing the OS of patients with unresectable pancreatic cancer (13). Moreover, the JASPAC 01 trial found that S-1 prior to GEM is effective as adjuvant chemotherapy for resected pancreatic cancer (14). However, there is no available third-line chemotherapy following GEM (plus cisplatin) and 5-FU for the treatment of patients with BTC.

PTX is isolated from the Western Yew, Taxus brevifolia (3). Similar to vinca alkaloids, PTX binds microtubules. However, while vinca alkaloids promote microtubule dissociation and disruption of the mitotic spindle, PTX promotes microtubule formation and stabilization. Retrospective studies, as well as phase I and II studies of PTX and docetaxel (taxanes) for the treatment of patients with pancreatic cancer and BTC (15-19), reported disease control rates of $33-57 \%$ when this regimen was used as first-line chemotherapy.

PTX is attracting increasing attention for its effects on pathological conditions other than cancer. For example, PTX is incorporated into drug-eluting stents placed in coronary arteries (20). Moreover, PTX ameliorates fibrosis in 
hepatic stellate cells and renal fibrosis through inhibition of TGF- $\beta /$ Smad activity $(6,7)$. Furthermore, PTX inhibits paracrine TGF- $\beta 1$ signaling between gallbladder epithelial cells and myofibroblasts (21).

PTX decreases interstitial fluid pressure and improves the oxygenation of breast cancer tissues in patients treated with neoadjuvant chemotherapy (22). To mitigate this problem, patients with hypoxic tumors, tumors with high interstitial fluid pressure, or both, were administered PTX chemotherapy (22). Thus, taxanes may be effective in treating hypoxic tumors, such as pancreatic cancer and BTC. For example, albumin-bound PTX + GEM therapy increases the treatment options for patients with pancreatic cancer (23), and this therapy causes stromal disrupting effects in these patients (24).

Taxane chemotherapy has been used to treat patients with GEM-refractory pancreatic cancer $(25,26)$. Anticancer drugs, irradiation, hypoxia, malnutrition and heat induce EMT, which is associated with the invasive potential of cancer cells (27). The inhibitory effect of PTX on TGF- $\beta /$ Smad activity contributes to the suppression of the EMT (8).

We previously reported that PTX was more effective in terms of time-to-treatment failure compared with GEM and S-1 for the treatment a patient with unresectable gallbladder cancer (9). Furthermore, low-dose PTX, which is associated with fewer side effects, should be used as palliative chemotherapy for patients with BTC; in addition, PTX was established as a palliative chemotherapy agent for treating patients with breast cancer (28). In the present phase I study, the efficacy and safety of weekly low-dose PTX as third-line chemotherapy for patients with BTC was demonstrated. The $50 \mathrm{mg} / \mathrm{m}^{2}$ of PTX was not MTD after 8 weeks of administration; however, a further dose increment, which would be required to treat patients with $\mathrm{RD}$, was not pursued. The intent of this therapy was palliative, aimed to be administered for as long as possible, safe and painless; therefore, the appropriate dose of PTX was terminated at $50 \mathrm{mg} / \mathrm{m}^{2}$. This dose may be referred to as minimum effective dose and it may be applied in palliative treatment.

In conclusion, following failure of therapy with GEM and 5-FU, palliative chemotherapy with low-dose PTX was found to be well-tolerated and safe, and may be effective for patients with unresectable or recurrent BTC. A future phase II study is required to confirm the effectiveness of low-dose PTX in this setting.

\section{References}

1. Xiu AX, Hong TS, Hezel AF and Kooby DA: Current management of gallbladder carcinoma. Oncologist 15: 168-181, 2010

2. Valle JW, Wasan H, Palmer DH, Cunningham D, Anthoney A, Maraveyas A, Madhusudan S, Iveson T, Hughes S, Pereira SP, et al: Cisplatin plus gemcitabine versus gemcitabine for biliary tract cancer. N Engl J Med 362: 1273-1281, 2010.

3. Gelmon K: The toxoids: Paclitaxel and docetaxel. Lancet 344: 1267-1272, 1994

4. Donaldson KL, Goolsby GL, Kiener PA and Wahl AF: Activation of p34cdc2 coincident with taxol-induced apoptosis. Cell Growth Differ 5: 1041-1050, 1994.

5. Schiff PB, Fant J and Horwitz SB: Promotion of microtubule assembly in vitro by taxol. Nature 277: 665-667, 1979 .

6. Zhang D, Sun L, Xian W, Liu F, Ling G, Xiao L, Liu Y, Peng Y, Haruna Y and Kanwar YS: Low-dose paclitaxel ameliorates renal fibrosis in rat UUO model by inhibition of TGF-beta/Smad activity. Lab Invest 90: 436-447, 2010.
7. Zhou J, Zhong DW, Wang QW, Miao XY and Xu XD: Paclitaxel ameliorates fibrosis in hepatic stellate cells via inhibition of TGF-beta/Smad activity. World J Gastroenterol 16: 3330-3334, 2010.

8. Hirose A, Tajima H, Ohta T, Tsukada T, Okamoto K, Nakanuma S, Sakai S, Kinoshita J, Makino I, Furukawa H, et al: Low-dose paclitaxel inhibits the induction of epithelial-mesenchymal transition in the human cholangiocarcinoma CCKS-1 cell line. Oncol Lett 6: 915-920, 2013.

9. Tajima H, Ohta T, Shinbashi H, Hirose A, Tsukada T, Okamoto K, Nakanuma S, Sakai S, Furukawa H, Makino I, et al: Successful treatment of unresectable gallbladder cancer with low-dose paclitaxel as palliative chemotherapy after failure of gemcitabine and oral S-1: A case report. Oncol Lett 4: 1281-1284, 2012.

10. Eienhauer EA, Therasse P, Bogaerts J, Schwartz LH, Sargent D, Ford R, Dancey J, Arbuck S, Gwyther S, Mooney M, et al: New response evaluation criteria in solid tumours: Revised RECIST guideline (version 1.1). Eur J Cancer 45: 228-247, 2009.

11. Ellis PA, Norman A, Hill A, O'Brien ME, Nicolson M, Hickish T and Cunningham D: Epirubicin, cisplatin and infusional 5-fluoroufacil (5-FU) (ECF) in hepatobiliary tumors. Eur J Cancer 31A: 1594-1598, 1995.

12. Patt YZ, Jones DV Jr, Hoque A, Lozano R, Markowitz A, Raijman I, Lynch P and Charnsangavej C: Phase II trial of intravenous fluorouracil and subcutaneous interferon alfa-2b for biliary tract cancer. J Clin Oncol 14: 2311-2315, 1996.

13. Ueno H, Ioka T, Ikeda M, Ohkawa S, Yanagimoto H, Boku N, Fukutomi A, Sugimori K, Baba H, Yamao K, et al: Randomized phase III study of gemcitabine plus S-1, S-1 alone, or gemcitabine alone in patients with locally advanced and metastatic pancreatic cancer in Japan and Taiwan: GEST study. J Clin Oncol 31: 1640-1648, 2013.

14. Uesaka K, Boku N, Fukutomi A, Okamura Y, Konishi M, Matsumoto I, Kaneoka Y, Shimizu Y, Nakamori S, Sakamoto $\mathrm{H}$, et al: Adjuvant chemotherapy of S-1 versus gemcitabine for resected pancreatic cancer: A phase 3, open-label, randomized, non-inferiority trial (JASPAC 01). Lancet 388: 248-257, 2016.

15. Papakostal P, Kouroussis C, Androulakis N, Samelis G, Aravantinos G, Kalbakis K, Sarra E, Souglakos J, Kakolyris S and Georgoulias V: First-line chemotherapy with docetaxel for unresectable or metastatic carcinoma of the biliary tract. A multicentre phase II study. Eur J Cancer 37: 1833-1838, 2001.

16. Okada S, Sakata Y, Matsuno S, Kurihara M, Sasaki Y, Ohashi Y and Taguchi T: Phase II study of docetacel in patients with metastatic pancreatic cancer: A Japanese cooperative study. Cooperative Group of Docetaxel for Pancreatic Cancer in Japan. Br J Cancer 80: 438-443, 1999.

17. Ryan DP, Kulke MH, Fuchs CS, Grossbard ML, Grossman SR, Morgan JA, Earle CC, Shivdasani R, Kim H, Mayer RJ and Clark JW: A Phase II study of gemcitabine and docetaxel in patients with metastatic pancreatic carcinoma. Cancer 94: 97-103, 2002

18. Jones DV Jr, Lozano R, Hoque A, Markowitz A and Patt YZ: Phase II study of paclitaxel therapy for unresectable biliary tree carcinomas. J Clin Oncol 14: 2306-2310, 1996.

19. Maeda S, Motoi F, Onogawa T, Morikawa T, Shigeru O, Sakata N, Takadate T, Naitoh T, Rikiyama T, Katayose Y, et al: Paclitaxel as second-line chemotherapy in patients with gemcitabine-refractory pancreatic cancer: A retrospective study. Int J Clin Oncol 16: 539-545, 2011.

20. Beak I, Bai CZ, Hwang J, Nam HY, Park JS and Kim DJ: Paclitaxel coating of the luminal surface of hemodialysis grafts with effective suppression of neointimal hyperplasia. J Vasc Surg 55: 806-814.e1, 2012.

21. Choi HS, Savard CE, Choi JW, Kuver R and Lee SP: Paclitaxel interrupts TGF-beta1 signaling between gallbladder epithelial cells and myofibroblasts. J Surg Res 141: 183-191, 2007.

22. Taghian AG, Abi-Raad R, Assaad SI, Casty A, Ancukiewicz M, Yeh E, Molokhia P, Attia K, Sullivan T, Kuter I, et al: Paclitaxel decreases the interstitial fluid pressure and improve oxygenation in breast cancer in patients treated with neoadjuvant chemotherapy: Clinical implications. J Clin Oncol 23: 1951-1961, 2005.

23. Von Hoff DD, Ramanthan RK, Borad MJ, Laheru DA, Smith LS, Wood TE, Korn RL, Desai N, Trieu V, Iglesias JL, et al: Gemcitabine plus nab-paclitaxel is an active regimen in patients with advanced pancreatic cancer: A phase I/II trial. J Clin Oncol 29: 4548-4554, 2011. 
24. Alvarez R, Musteanu M, Garcia-Garcia E, Lopez-Casas PP, Megias D, Guerra C, Muňoz M, Quijano Y, Cubillo A, Rodoriguez-Pascual J, et al: Stromal disrupting effects of nab-paclitaxel in pancreatic cancer. Br J Cancer 109: 926-933, 2013.

25. Shukuya T, Yasui H, Boku N, Onozawa Y, Fukutomi A, Yamazaki K, Taku K, Kojima T and Machida N: Weekly paclitaxel after failure of gemcitabine in pancreatic cancer patients with malignant ascites: A retrospective study. Jpn J Clin Oncol 40: 1135-1138, 2010.

26. Cereda S and Reni M: Weekly docetaxel as salvage therapy in patients with gemcitabine-refractory metastatic pancreatic cancer. J Chem 20: 509-512, 2008.
27. Tajima H, Ohta T, Makino I, Hayashi $H$, Nakagawara $H$, Onishi I, Takamura H, Ninomiya I, Kitagawa H, Fushida S, et al: Expression of epithelial-mesenchymal transition markers in locally recurrent hepatocellular carcinoma after radiofrequency ablation. Exp Therap Med 1: 347-350, 2010.

28. Schrama JG, de Boer MM, Baars JW, Schornagel JH and Rodenhuis S: Palliative chemotherapy after failure of high-dose chemotherapy in breast cancer-toxicity and efficacy. Anticancer Res 23: 2795-2800, 2003. 